\title{
EFFECTS OF WET-DRY ALTERNATION OF OCEAN TIDE ENVIRONMENTS ON THE BOND BEHAVIOUR OF CFRP-REINFORCED CORAL CONCRETE
}

\author{
PING WU*, "YIDONG XU*,**, WEIGUO YOU*,***, YONG QIU****, YUEFENG DU**** \\ *School of Civil Engineering \& Architecture, NingboTech University, Ningbo 315100, China \\ **Ningbo Research Institute, Zhejiang University, Ningbo 315100, China \\ ***School of Civil Engineering, Chongqing Jiaotong University, Chongqing 400074, China \\ ****Zhejiang Provincial Erjian Construction Group Ltd, Ningbo 315202, China \\ "E-mail: xyd@nit.zju.edu.cn
}

Submitted November 28, 2020; accepted January 8, 2021

\begin{abstract}
Keywords: CFRP, Coral aggregate concrete, Marine environment, Bond damage variable, Bond-slip constitutive model
In this paper, the dry-wet cycle test in $\mathrm{NaCl}$ solutions is used to simulate ocean tide attack, and the pull-out test is carried out to explore the changes in the bond behaviour of CFRP-reinforced coral concrete under the attack of the simulated ocean tide environment. As shown by the results, with the increase in the number of dry-wet cycles, the bond strength of CFRPreinforced coral concrete will first increase and then decrease. Based on damage mechanics theory, the deterioration of the interfacial bond properties between CFRP bars and coral concrete under the attack of the ocean tide environment is analysed. By fitting the obtained data, the bond-slip equation of the CFRP-reinforced coral concrete with different damage degrees is obtained, and the related bond-slip constitutive model considering damage effects is established.
\end{abstract}

\section{INTRODUCTION}

With the rapid development of China's economy, the land infrastructure is gradually improving, and it is imperative to increase the development and utilization of island resources. In the process of offshore island construction, concrete is the most used building material, and large amounts of it are used. Using conventional aggregate to prepare concrete will greatly increase the project cost [1]. Using coral aggregate around offshore islands and reefs to prepare coral concrete can effectively solve the problem mentioned above [2, 3]. Zhou [4] derived the constitutive relations of coral aggregate concrete under uniaxial and triaxial compression. Chen [5] experimentally studied the curing effect on the mechanical properties of cement-stabilized coral sand. By using the digital image correlation (DIC) method, Liu [6] obtained the strain fields on the surface of carbon fibre-reinforced coral concrete and analysed the flexural damage process. The abovementioned studies, however, are mainly focused on the mechanical properties of coral concrete.

Since coral aggregate contains a large amount of chloride ions [7], steel bars easily corrode in concrete. How to avoid the deterioration of the coral concrete durability caused by reinforcement corrosion has attracted much attention. Zhang [8] investigated the corrosion behaviour of low alloy steel bars containing $\mathrm{Cr}$ and $\mathrm{Al}$ in coral concrete for ocean construction. Liu [9] investigated the mechanical properties and microstructure of carbon fibre-reinforced coral concrete. Many studies indicated that fibre-reinforced polymer (FRP) bars have excellent mechanical properties and durability [10-12], which provides a new method to solve the corrosion problem of offshore island infrastructure. Li [13] investigated the mechanical properties of basalt fibre-reinforced polymer (BFRP) bars in coral concrete under high temperature and humidity. The results show that the temperature considerably influenced the tensile strength of the BFRP bars. Tang[14] introduced carbon fibrereinforced polymer (CFRP) into geopolymeric recycled aggregate concrete. The failure patterns of CFRP-confined geopolymeric recycled aggregate concrete under both static and cyclic compression loading were investigated and compared.

Note that the effective bonding between FRP bars and coral concrete is an important basis for their joint work. Whether harsh marine environments will lead to the deterioration of the bond performance between FRP bars and coral concrete is a problem worthy of attention. However, the deterioration of the bond behaviour between FRP bars and coral concrete in a real marine environment has not been thoroughly discussed, apart from a few exceptions [15-18]. In this paper, the bonding performance test of CFRP-reinforced coral concrete under the corrosion of an ocean tide environment was 
carried out, and the bonding degradation mechanism was revealed. Based on damage mechanics, a damage variable that can reflect the deterioration of the bond performance of the CFRP-reinforced coral concrete interface is defined. By fitting the obtained data, the bond-slip equation of the CFRP-reinforced coral concrete under the attack of an ocean tide environment is established, and the related bond-slip constitutive model considering damage effects is obtained.

\section{EXPERIMENTAL}

\section{Materials and mix proportions}

The designed compressive strength of coral concrete is $30 \mathrm{MPa}$. The adopted cement binders are ordinary Portland cement (Type 42.5), fly ash (FA, Grade I) and granulated blast furnace slag (GBFS, Grade S95). The fine aggregate used is quartz sand. The coarse aggregate used is coral aggregate that is crushed and sieved to obtain a diameter of $5-25 \mathrm{~mm}$, as shown in Figure 1 . The physical properties of coral coarse aggregate were tested, and the detailed properties are listed in Table 1.

The micromorphology of the coral aggregate was observed by scanning electron microscopy (SEM). As shown in Figure 2, the surface of coral aggregate is rough, and there are many internal pores. On the one hand, the porous structure facilitates the nesting of coral aggregate and cement paste to form a mechanical meshing structure, which is easier to develop the strength of the interface transition zone. On the other hand, the rough surface and high water absorption of coral coarse aggregate may reduce the workability of concrete. To ensure the workability of coral concrete, liquid polycarboxylate-based superplasticizer is added. The mix proportion of coral concrete is shown in Table 2.

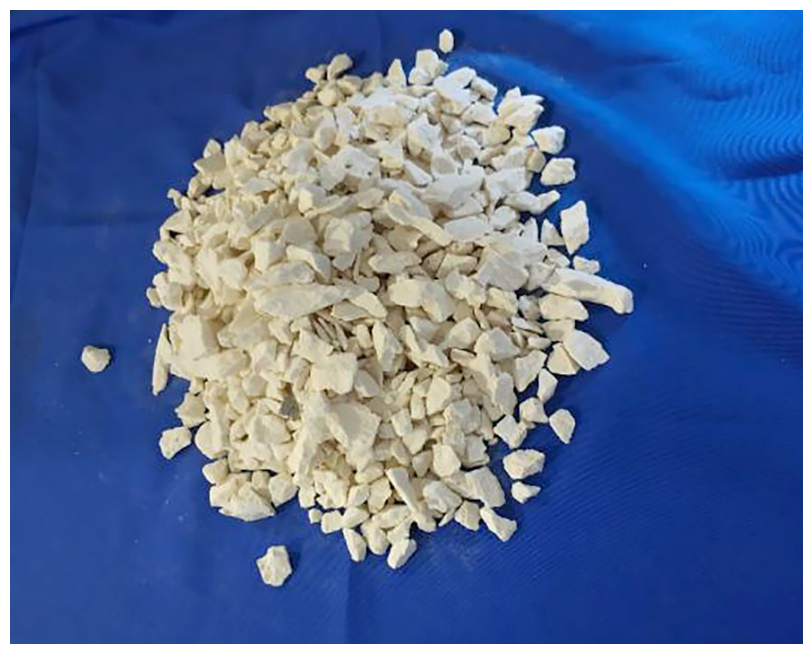

Figure 1. Coral coarse aggregate.

Table 1. Properties of coral coarse aggregate.

\begin{tabular}{cccccc}
\hline $\begin{array}{c}\text { Apparent } \\
\text { density } \\
\left(\mathrm{kg} \cdot \mathrm{m}^{-3}\right)\end{array}$ & $\begin{array}{c}\text { Bulk } \\
\text { density } \\
\left(\mathrm{kg} \cdot \mathrm{m}^{-3}\right)\end{array}$ & $\begin{array}{c}\text { Porosity } \\
(\%)\end{array}$ & $\begin{array}{c}\text { Cylinder } \\
\text { compression } \\
\text { strength }(\mathrm{MPa})\end{array}$ & $\begin{array}{c}\text { Chloride ion } \\
\text { content } \\
(\%)\end{array}$ & $\begin{array}{c}\text { Water absorption } \\
\text { for } 1 \mathrm{~h} \\
(\%)\end{array}$ \\
\hline 2135 & 1018 & 56.82 & 3.90 & 0.07 & 16.3 \\
\hline
\end{tabular}

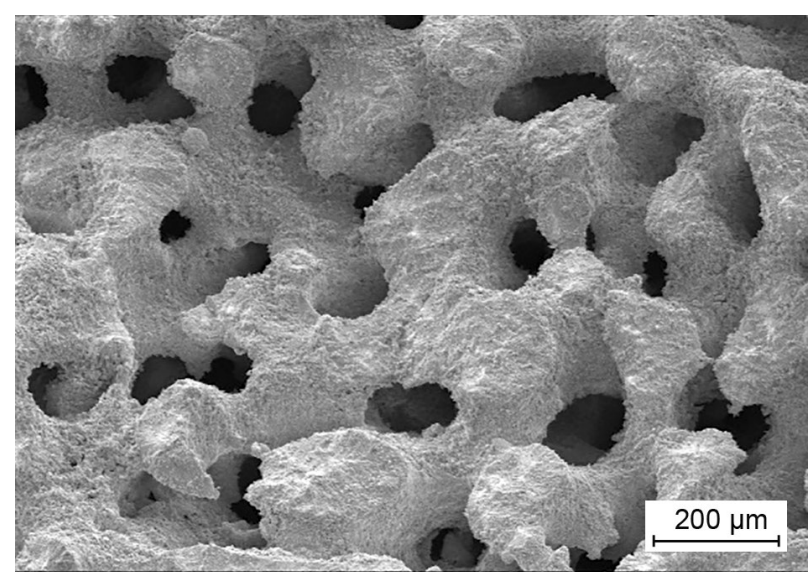

a) Magnified 100 times

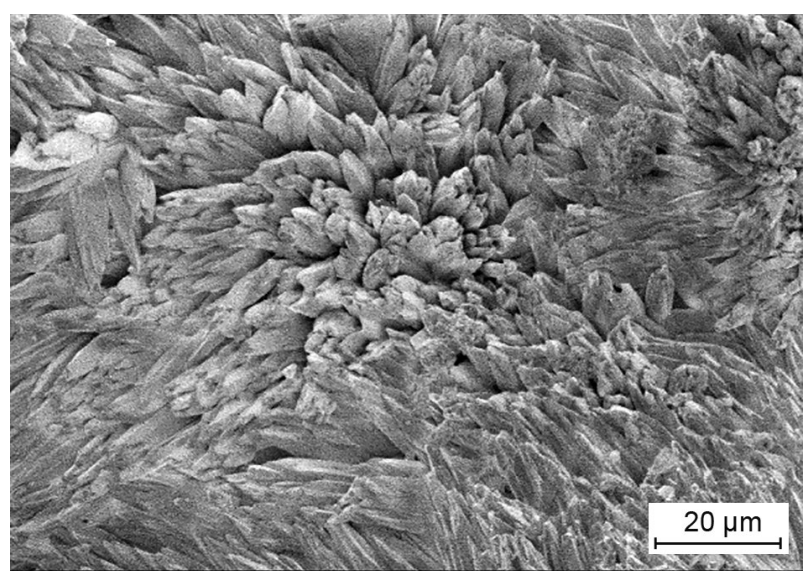

b) Magnified 1000 times

Figure 2. Morphology of coral coarse aggregate.

Table 2. Mix proportion of coral concrete $\left(\mathrm{kg} \cdot \mathrm{m}^{-3}\right)$.

\begin{tabular}{ccccccc}
\hline Cement & FA & GBFS & Fine aggregate & Coarse aggregate & Water & Superplasticizer \\
\hline 390 & 80 & 50 & 600 & 855 & 177 & 7.8 \\
\hline
\end{tabular}

Ceramics - Silikáty 65 (1) 98-106 (2021) 
The CFRP bar used here was produced by Zhejiang Haining Anjie Composite Material Co., Ltd., as shown in Figure 3. The diameter of the CFRP bar is $8 \mathrm{~mm}$, and the ultimate strength of the CFRP bar is $1191 \mathrm{MPa}$.

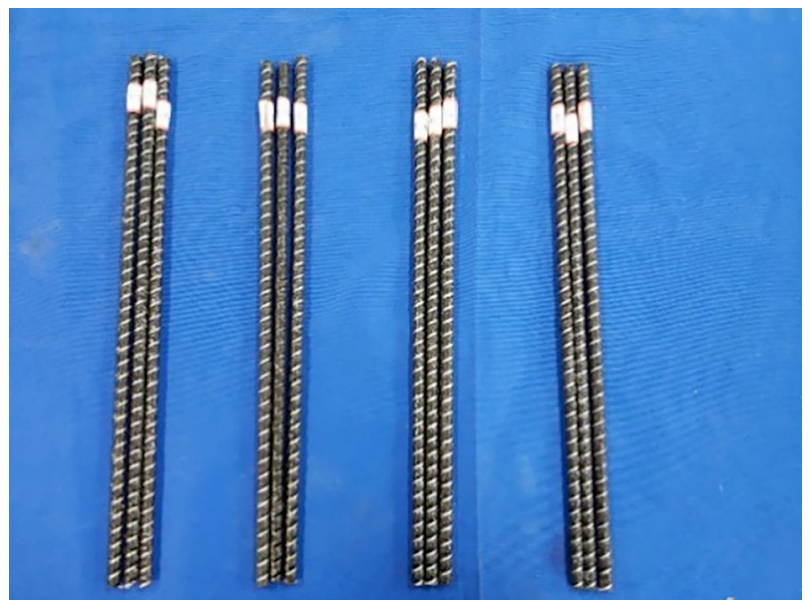

Figure 3. CFRP Bars.

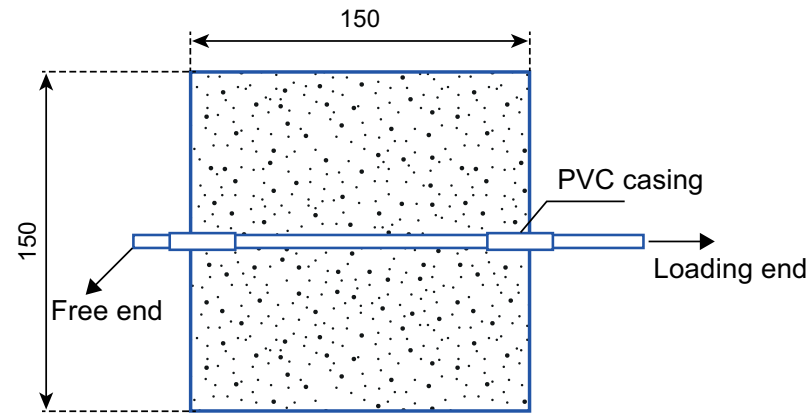

a) Schematic illustration of the pull-out specimen

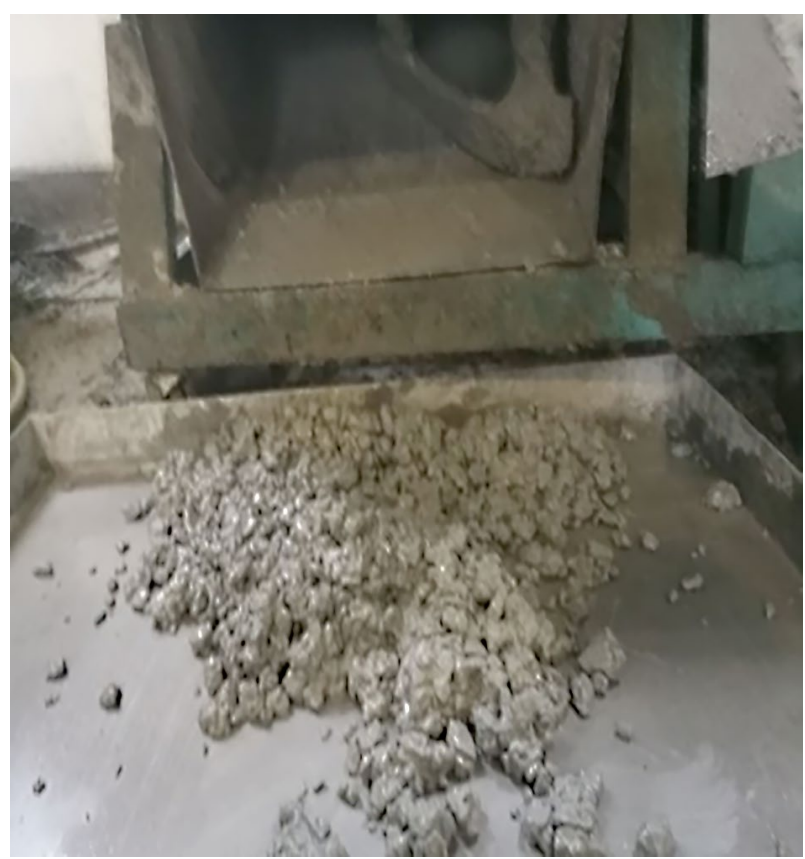

c) Coral concrete preparation

\section{Specimens}

The specimens used for the pull-out test were prepared according 'Standard for test method of concrete structures' (GB/T 50152-2012). The details of the preparation process and sizes of the test specimen are shown in Figure 4. The CFRP bar was uniaxially embedded in the centre of a coral concrete cubic specimen with a size of $150 \times 150 \times 150 \mathrm{~mm}$ and bond length of $40 \mathrm{~mm}$. Four groups of pull-out specimens were casted, and the details are listed in Table 3. After air curing for 1 day, the specimens were demoulded and then cured for 28 days under standard room curing conditions of $20 \pm 2{ }^{\circ} \mathrm{C}$ and relative humidity of $95 \%$. After that, the specimens were sent to the ocean tidal environment simulation pool for an accelerated corrosion test.

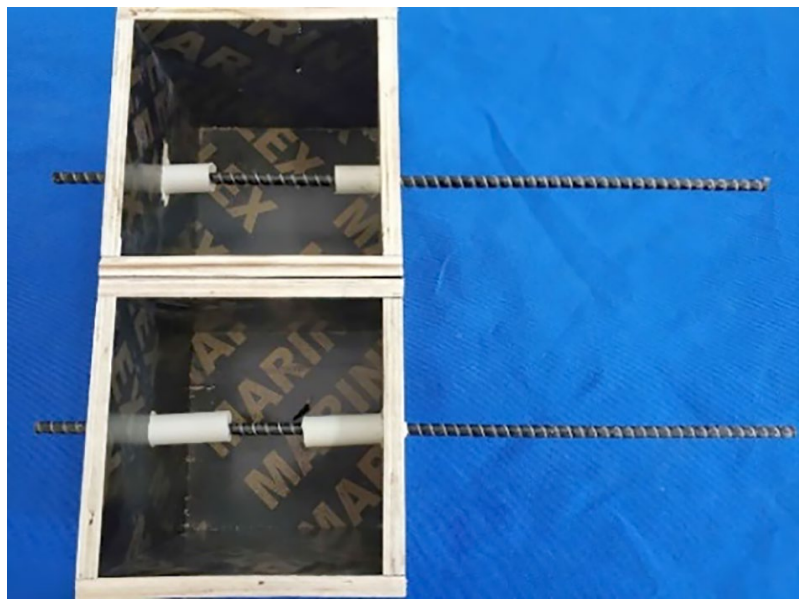

b) Wood mould used for the pull-out specimen

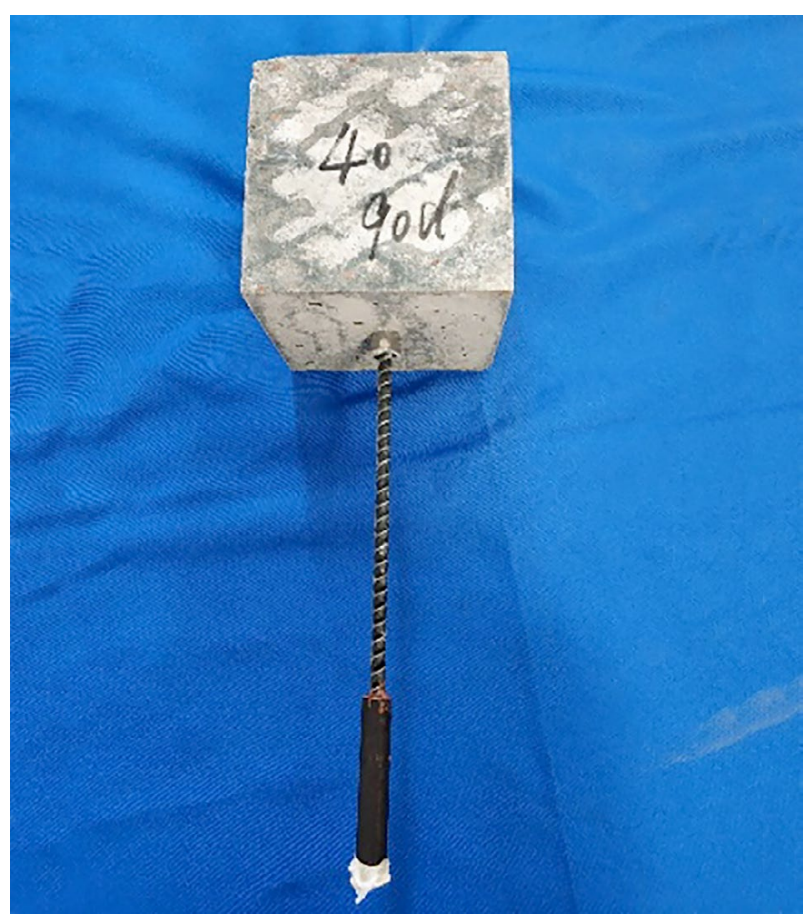

d) Pull-out specimen

Figure 4. The preparation of pull-out specimens. 
Table 3. Details of pull-out specimens.

\begin{tabular}{lcc}
\hline Specimen ID & $\begin{array}{c}\text { Bond length } \\
(\mathrm{mm})\end{array}$ & $\begin{array}{c}\text { Duration of } \\
\text { dry-wet cycles }(\mathrm{d})\end{array}$ \\
\hline C8-40-0 & 40 & 0 \\
C8-40-30 & 40 & 30 \\
C8-40-60 & 40 & 60 \\
C8-40-90 & 40 & 90 \\
\hline
\end{tabular}

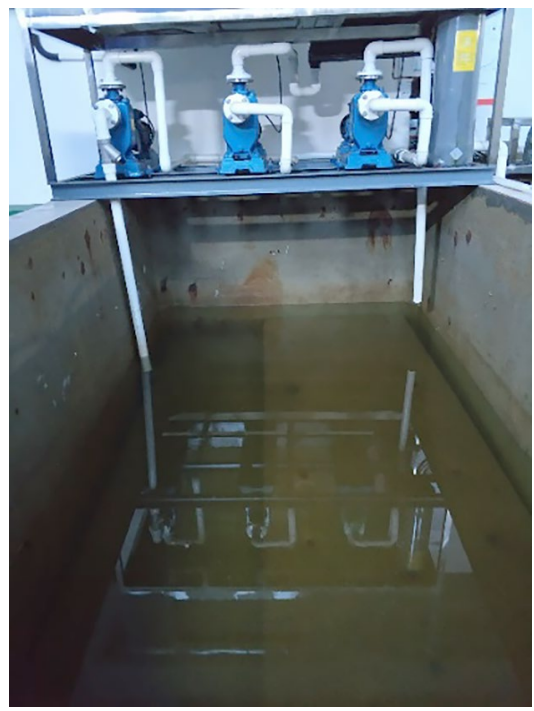

a) ZXC ocean tidal environment simulation pool

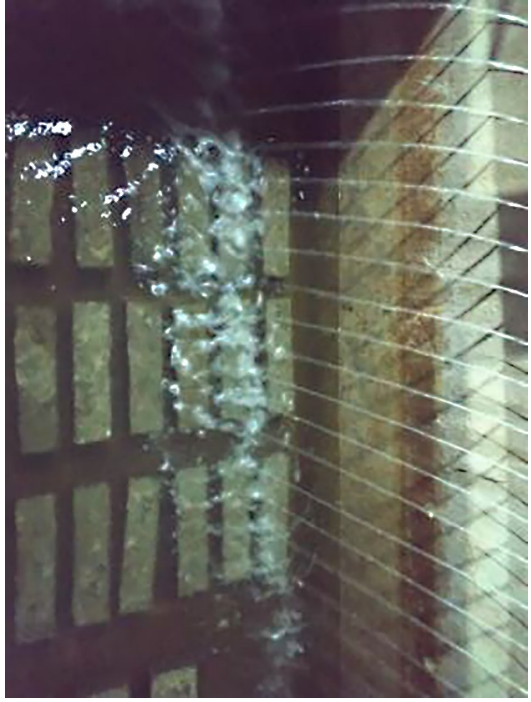

b) Seawater flooding process
Test procedures

1) Accelerated corrosion test in an alternation dry-wet ocean tidal environment: A ZXC ocean tidal environment simulation pool, which is specially developed by Torrent Instrument Co., Ltd., Shanghai, was adopted to perform the accelerated corrosion test. A $3.5 \% \mathrm{NaCl}$ solution was used to simulate seawater

Figure 5. ZXC ocean tidal environment of the simulation pool.

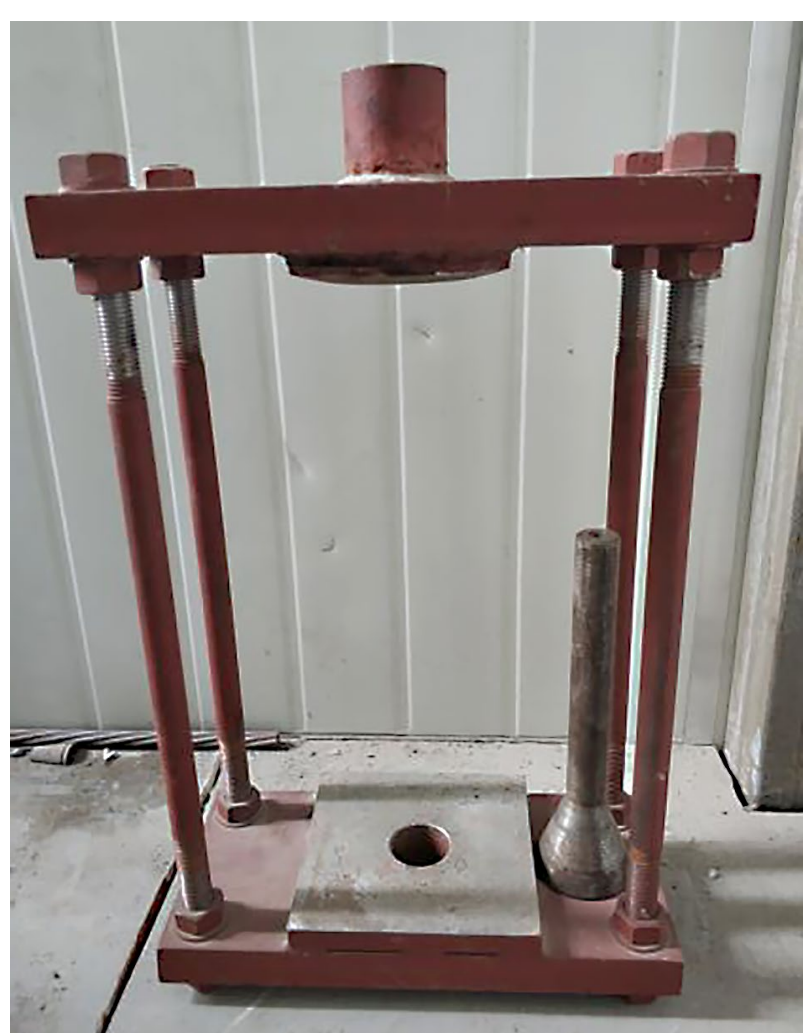

a) Cage loading equipment

Figure 6. Pull-out test used for CFRP-reinforced coral concrete.

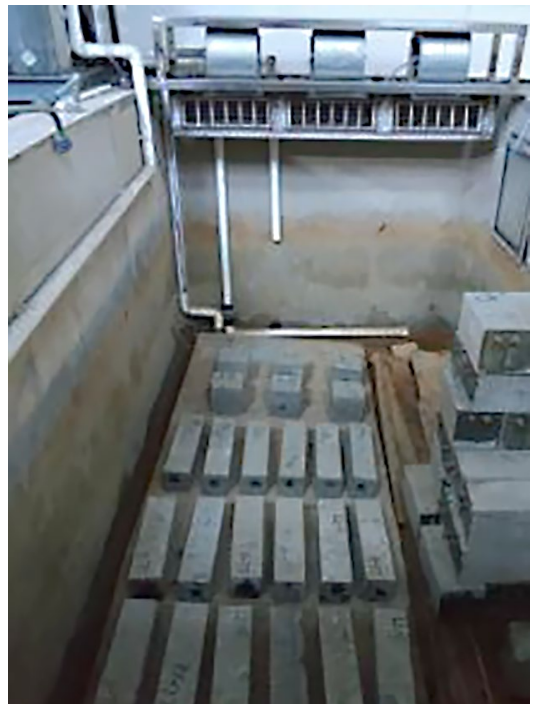

c) Drying process

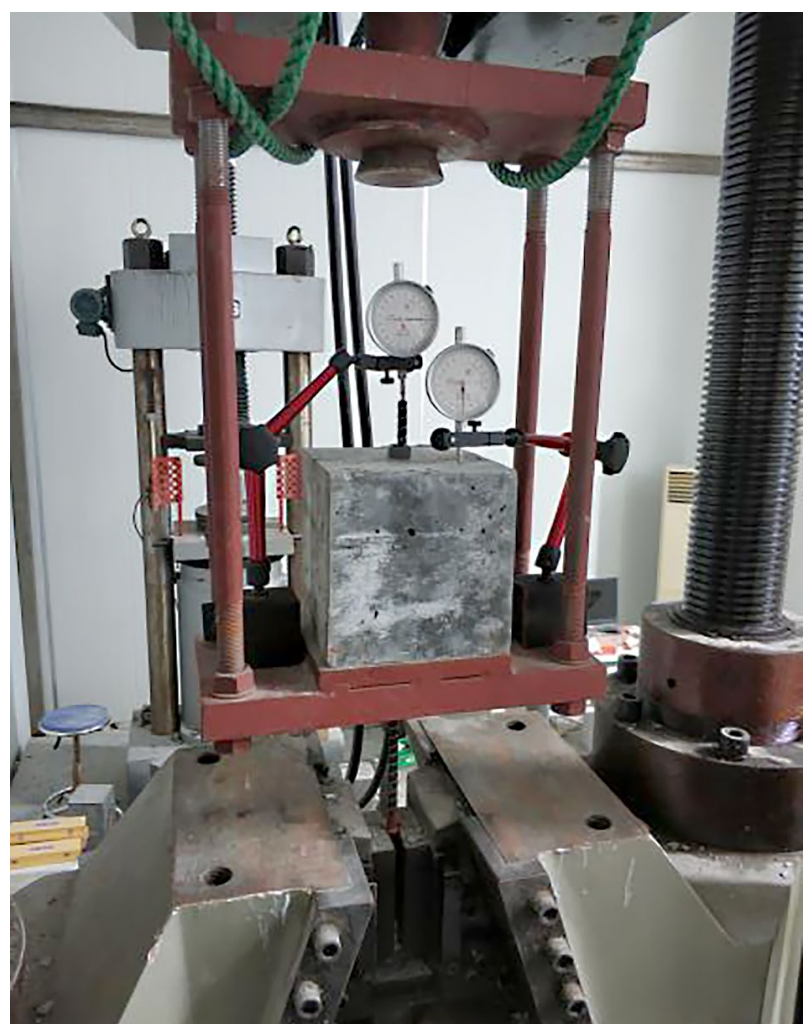

b) The pull-out test setup 
[19]. The dry-to-wet time ratio was 0.391 , that is, 864 minutes of drying, 554 minutes of soaking, and a dry-wet cycle once a day, as shown in Figure 5. The designed duration of dry-wet cycles was $30 \mathrm{~d}$, $60 \mathrm{~d}$ and $90 \mathrm{~d}$.

2) Pull-out test: Figure 6 shows the loading device used for the pull-out test of CFRP-reinforced coral concrete, which is composed of four high-strength screws, a top plate, a bottom plate and a metal cylinder. The pull-out test was performed by using a WAW-1000 electro-hydraulic servo universal testing machine. The loading process was controlled by displacement, and the deformation rate was $0.3 \mathrm{~mm} \cdot \mathrm{min}^{-1}$.

\section{Bond behaviour of CFRP-reinforced coral concrete}

Figure 7 shows the interface of coral concrete and CFRP after the pull-out test. Due to the adoption of the central pull-out testing method, the concrete cover is thick, in which case the failure mode of all the specimens is pull-out failure for the CFRP bars from coral

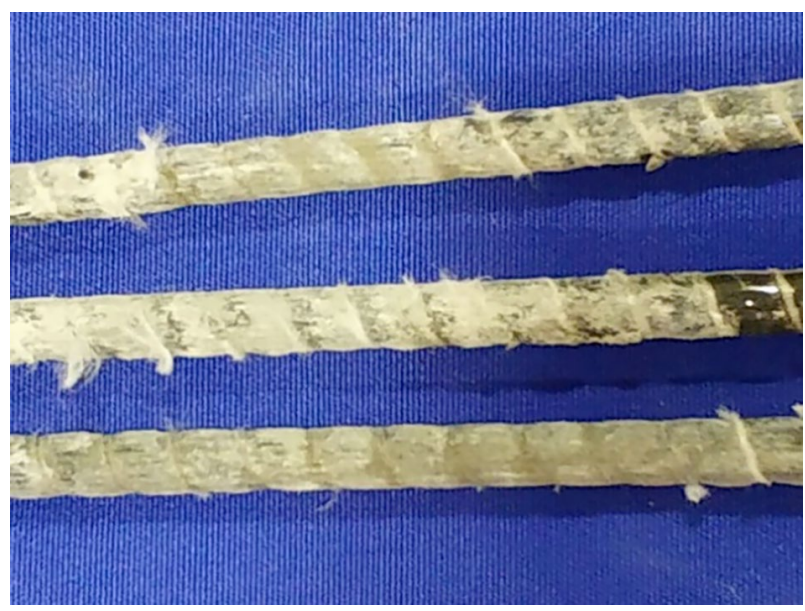

a) CFRP

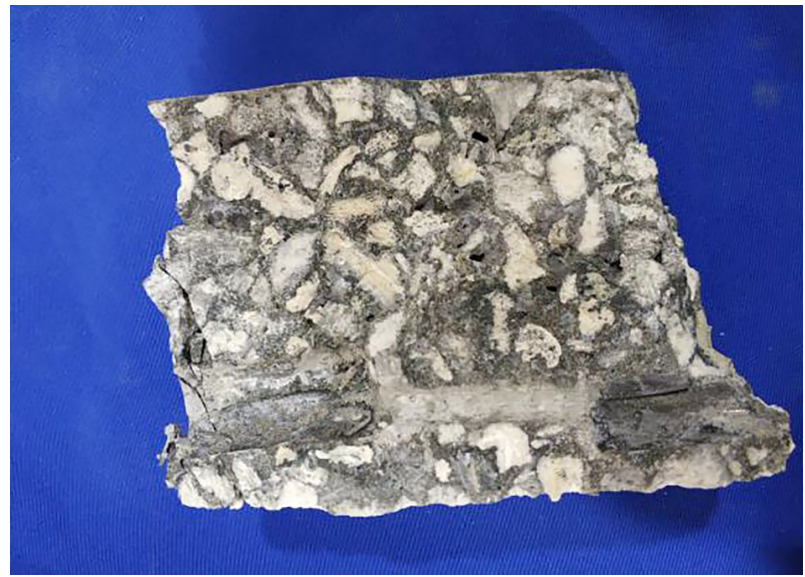

b) Coral concrete

Figure 7. Interface of coral concrete and CFRP after the pullout test. concrete [18]. When the CFRP bars are pulled out, the coral concrete around the CFRP bars are sheared, and the surface of the CFRP bars in the bonding part is obviously worn. As shown in Figure 7, the CFRP ribs of the bonding section have been smoothed, and the yarns wound around the bonding section are also broken. The residual yarn can be seen in the coral concrete bonding area.

The bond-slip curve of coral concrete with CFRP bar can be divided into four stages [20], as shown in Figure 8.

1) Slight-slip stage: At the beginning of the test, the slip at the loading end of the CFRP bars is very small, and there is no slip at the free end. At this stage, the bond strength between the CFRP bars and coral concrete is mainly a chemical adhesive force. As seen from the figure, the $\tau$-s curve at this stage is a straight line that approximates the origin.

2) Slip stage: As the load increases, the chemical adhesive force between the CFRP bar and coral concrete gradually weakens, the free end begins to move, and the slope of the bond-slip curve begins to slowly decrease. At this stage, the adhesive force between the CFRP and coral concrete is provided by the mechanical occlusal force and friction force.

3) Descending stage: When the ultimate bond strength is reached, the amount of slip between the loading end and the free end increases sharply, causing serious damage to the surface ribs of the CFRP bar due to friction, and the mechanical occlusal force decreases. The bond strength between the CFRP bar and coral concrete continues to decrease, and the coral concrete around the CFRP bars is damaged by shearing. At this stage, the slope of the $\tau$ - $s$ curve becomes negative.

4) Residual stage: At this stage, the slip value continues to increase rapidly, and the bond strength will change back and forth. When the bond strength decreases to

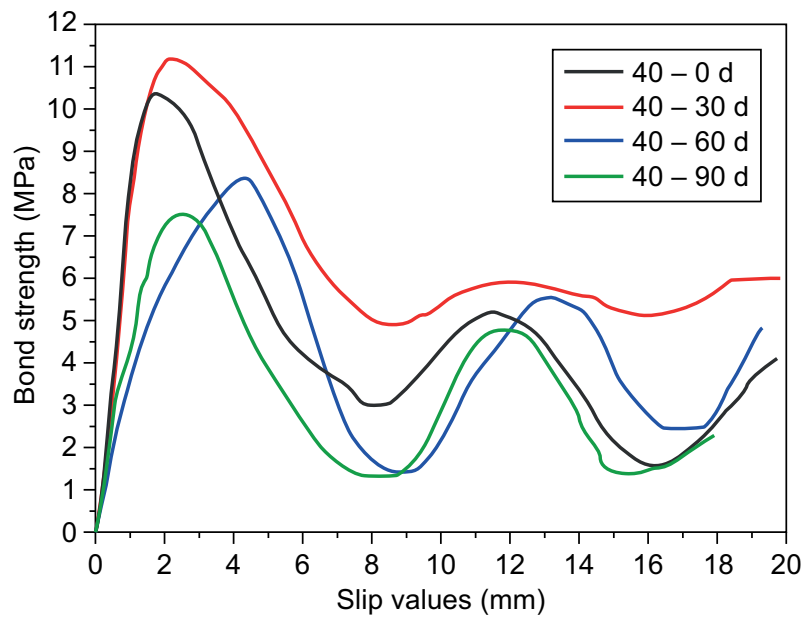

Figure 8. Bond-slip curve of CFRP-reinforced coral concrete. 
a peak value, it will continue to increase and enter into another cycle of the slip stage. After reaching the next ultimate bond strength, the bond strength begins to decrease again. The process is repeated until the CFRP bars are completely pulled out. The bond-slip curve is similar to a sine function curve. The reason for this is that the ribs on the surface of the CFRP bars are relatively smooth, and the height of the rib is low. During the pull-out process, the coral concrete between the ribs will not be completely sheared, and there is still a residual mechanical occlusal force and friction force.

Table 4 shows the detailed data of the pull-out testing of CFRP-reinforced coral concrete. As the dry-wet cycle progresses, the bond strength of CFRP-reinforced coral concrete will first increase and then decrease. The bond strength of the C8-40-30 specimen group is $7.9 \%$ higher than that of the C8-40-0 specimen group. However, the bond strengths of the C8-40-60 and C8-4-90 specimen group are $19.01 \%$ and $27.51 \%$ lower than the bond strength of the reference specimen group, respectively.

Table 4. Date of the pull-out testing of CFRP-reinforced coral concrete.

\begin{tabular}{lccc}
\hline $\begin{array}{l}\text { Specimen } \\
\text { ID }\end{array}$ & $\begin{array}{c}\text { Duration of } \\
\text { dry-wet cycling } \\
\text { (d) }\end{array}$ & $\begin{array}{c}\text { Ultimate bond } \\
\text { strength } \\
(\mathrm{MPa})\end{array}$ & $\begin{array}{c}\text { Rate of } \\
\text { change } \\
(\%)\end{array}$ \\
\hline C8-40-0 & 0 & 10.36 & 0 \\
C8-40-30 & 30 & 11.18 & 7.9 \\
C8-40-60 & 60 & 8.39 & -19.01 \\
C8-40-90 & 90 & 7.51 & -27.51 \\
\hline
\end{tabular}

As for the reinforced concrete structure in the marine environment, a small amount of reinforcement corrosion products in the early stage of corrosion will produce a certain amount of expansion, which increases the friction between the reinforcement and concrete, resulting in an increase in the interfacial bond strength [21]. The influence of corrosion time on the bond behaviour between the CFRP bar and coral concrete can also be explained according to the above description. In the initial stage of the dry-wet cycle, chloride crystal products will fill the pores between the CFRP bars and concrete, which can increase the compactness of the interface between coral concrete and CFRP bars, thus increasing the bond strength of CFRP-reinforced coral concrete. With the increase in the wet-dry cycle time, the crystalline salt is continuously enriched, and then, expansion stress is generated. When the ultimate tensile stress of the coral concrete is less than the expansion stress, microcracks appear in the coral concrete. After cracks appear at the interface between CFRP tendons and coral concrete, debonding easily occurs, which leads to a gradual decrease in bonding strength.

\author{
Bond-slip model considering \\ damage effects for CFRP-reinforced \\ coral concrete interfaces
}

Damage mechanics is a relatively new subject. One of the aims of this subject is to investigate the relationship between the macro- and micromaterial characteristics, in which the former is related to the mechanical weakening of the material, and the latter is associated with the many randomly distributed microcracks with irregular shapes, sizes and orientations. The key to developing such a relationship is the definition and selection of damage variables, which, at present, has no clear criteria to follow $[22,23]$. It is generally recognized that a damage variable should be able to reflect the material characteristics at different scale levels, such as micro-, meso- and macroscales [24]. Here, the bonding interface between CFRP tendons and coral concrete is regarded as a new material with specific properties. When the bonding interface is in a non-destructive state, the interface bonding performance parameter is $B$; when in a damaged state, the interface bonding performance parameter is $B^{\prime}$. The damage variable is defined as

$$
D=\frac{B-B^{\prime}}{B}
$$

where $D$ is the interfacial bond damage variable. When $B^{\prime}=B$ and $D=0$, the bonding interface is not damaged; when $B^{\prime}=0$ and $D=1$, the bonding interface is in a completely damaged state; when $0<D<1$, there are different degrees of damage at the interface.

As discussed in section 3, the bond-slip curve of CFRP-reinforced coral concrete has four different stages, in which the first three stages are of concern in practical applications. Figure 9 illustrates the establishment of the bonding damage variable of CFRP-reinforced coral concrete. As the amount of slip increases, the slope of the bond-slip curve and the slope of the secant line both decrease. Theoretically, the decrease can be regarded as the attenuation process of the bond strength between

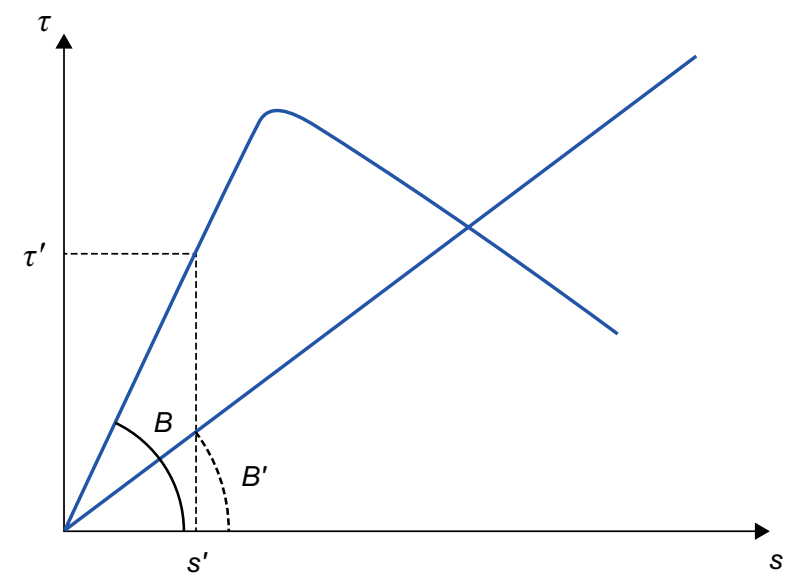

Figure 9. Schematic illustration of the bonding damage variable. 
CFRP bars and coral concrete. It can be seen from the figure that the slope of the curve is positive in both the slight-slip stage and the slip stage. However, the slope of the curve becomes negative in the descending stage. In the process of bond damage analysis, the positive and negative changes of the slope of the curve will increase the difficulty of analysis. Since the secant slope is always positive, it can be used as an index to evaluate the interfacial bonding performance, which can greatly reduce the difficulty of analysis. The physical meaning of the index is the bond stress corresponding to the unit slip resistance, as shown in Equation 2, where $\tau$ is bond stress, and $\mathrm{s}$ is the amount of slip. The secant slope of the $\tau$-s curve, $B^{\prime}$, is also the interface bonding performance parameter, as shown in Equation 1. As shown in Figure 9, in the initial slight-slip stage of $\left(0, s^{\prime}\right)$, the development of the bond strength between the CFRP bar and the coral concrete is in the elastic stage without damage expansion, in which case the bond performance coefficient $B$ is constant in the initial slight-slip stage. With the increase in loading, the $\tau$-s curve develops to the descending stage, which indicates that the interfacial bond strength

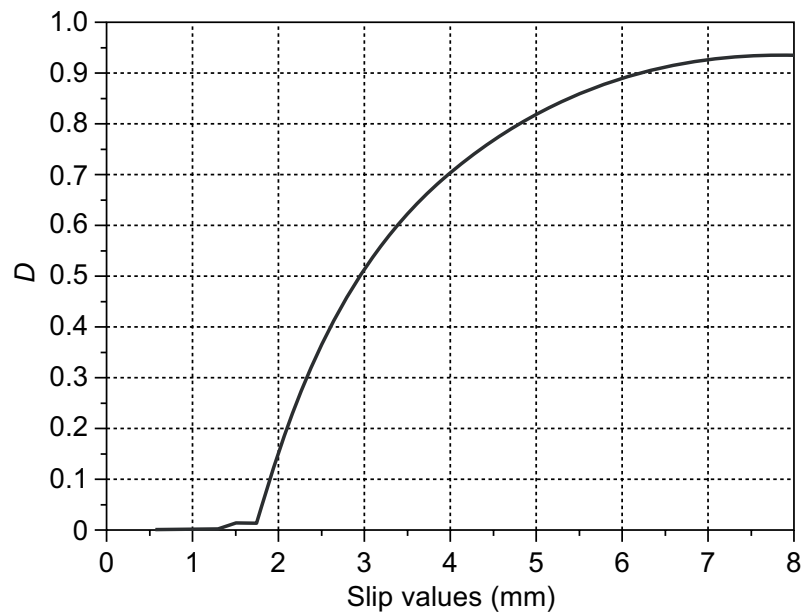

a) $0 \mathrm{~d}$

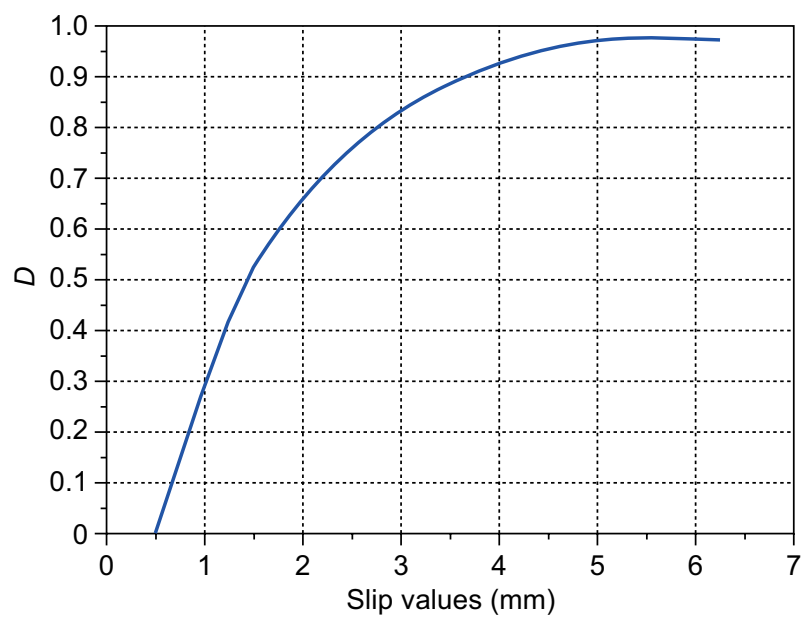

c) $60 \mathrm{~d}$ exceeds the elastic range, interface damage begins to develop, and the secant modulus decreases continuously.

$$
\tau=B^{\prime} s
$$

According to Equation 1, combined with the principle of strain equivalence, it is assumed that the amount of slip corresponding to the initial nominal bond stress on the damaged interface of the material is equal to the amount of slip corresponding to the effective bond stress on the non-destructive interface of the material. Then,

$$
s=\frac{\tau^{\prime}}{B}=\frac{\tau}{B^{\prime}}
$$

The bond-slip damage model can be expressed as Equation 4:

$$
\tau= \begin{cases}s \times B & \left(0<s<s^{\prime}\right) \\ s \times B^{\prime} & \left(s^{\prime}<s\right)\end{cases}
$$

Since $B^{\prime}=B(1-D)$,

$$
s=\frac{\tau}{B(1-D)}
$$

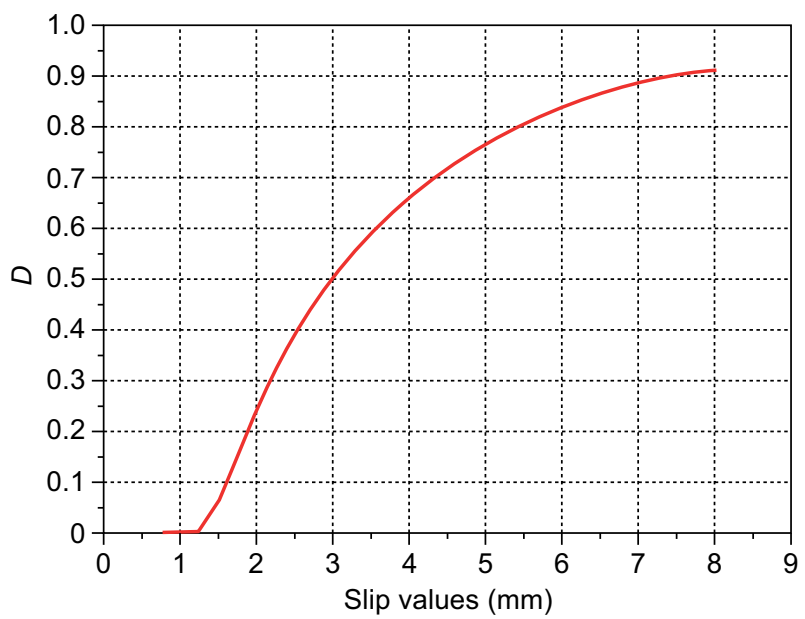

b) $30 \mathrm{~d}$

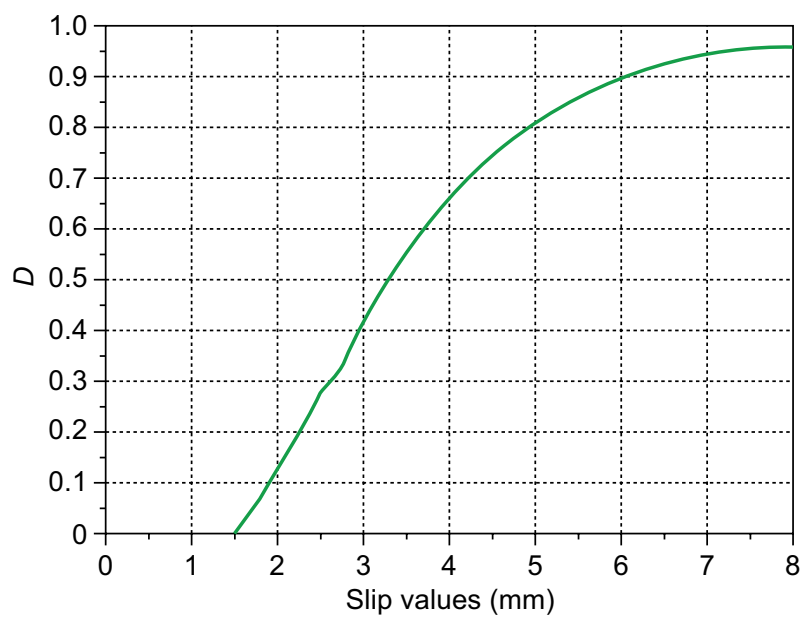

d) $90 \mathrm{~d}$

Figure 10. Damage variable evolution curve of CFRP-reinforced coral concrete in an alternating dry/wet ocean tidal environment. 
The bonding damage variable is shown in Equation 6.

$$
D=\left\{\begin{array}{cl}
0 & \left(0<s<s^{\prime}\right) \\
1-\left(\frac{\tau}{\mathrm{s}}\right) \div B & \left(s^{\prime}<s\right)
\end{array}\right.
$$

According to the bond slip curve, the initial value of slope $B$ can be obtained, and then, the damage amount under different dry-wet cycle times can be calculated by Equation 6 . The damage variable evolution curve is shown in Figure 10.

The interfacial bond damage variable $D$ is analysed by adopting the area definition method, as shown in Equation 7.

$$
D=\frac{A_{S}^{\prime}}{A_{d}}
$$

where $A_{s}^{\prime}$ is the reduction in the effective bonding interface area of CFRP-reinforced coral concrete; and $A_{d}$ is the effective interface area of CFRP-reinforced coral concrete after dry-wet cycling.

Since the value of $A_{s}^{\prime}$ is closely related to the slip value $s$,

$$
d A_{s}^{\prime}=B^{\prime} \times d s
$$

As shown in Figure 9, in the descending section of the curve, the $B$ 'value changes nonlinearly with the increase in slip value $s$. When $s$ increases, $B^{`}$ decreases gradually, so

$$
B^{\prime}=\frac{1}{p+Q \times s}
$$

where $p$ and $Q$ are constants.

By introducing Equation 9 into Equation 8, we can get the following results:

$$
d A_{s}^{\prime}=\frac{1}{p+Q \times s} \times d s
$$

Through an indefinite integral, Equation 11 can be obtained:

$$
A_{s}^{\prime}=\frac{1}{Q} \ln (p+Q \times s)+C_{1}
$$

where $C_{1}$ is constant.

By introducing Equation 11 into Equation 7,

$$
D=\frac{1}{A_{d}}\left[\frac{1}{Q} \ln (p+Q \times s)+C_{1}\right]
$$

After simplification, Equation 13 can be obtained:

$$
D=\ln (M+N \times S)
$$

where $M$ and $N$ are constants.

Equation 13 is used to fit the bond damage variable $D$ shown in Figure 10. The damage variable evolution models obtained at different corrosion ages are shown in Equations 14-17.
$0 \mathrm{~d}: \quad D=\left\{\begin{array}{l}0(0<s<1.25) \\ \ln (0.246+0.464 s)(1.25<s<4) \\ \ln (1.569+0.134 s)(4<s<8)\end{array}\right.$

$30 \mathrm{~d}: \quad D=\left\{\begin{array}{l}0(0<s<0.75) \\ \ln (0.575+0.345 s)(0.75<s<4.5) \\ \ln (1.513+0.129 s)(4.5<s<8)\end{array}\right.$

$60 \mathrm{~d}: \quad D=\left\{\begin{array}{l}0(0<s<0.85) \\ \ln (0.884+0.460 s)(0.85<s<4.25) \\ \ln (2.37+0.051 s)(4.25<s<6)\end{array}\right.$

$90 \mathrm{~d}: \quad D=\left\{\begin{array}{l}0(0<s<1.6) \\ \ln (0.433+0.362 s)(1.6<s<5.75) \\ \ln (1.935+0.088 s)(5.75<s<8)\end{array}\right.$

By substituting bond damage variable $D$ into Equation 6 , the bond-slip constitutive equation considering damage is obtained, as shown in Equations 18-21.

$0 \mathrm{~d}: \tau=\left\{\begin{array}{l}6.132 s(0<s<1.25) \\ 6.132 s[1-\ln (0.246+0.464 s)](1.25<s<4) \\ 6.132 s[1-\ln (1.569+0.134 s)](4<s<8)\end{array}\right.$

$30 \mathrm{~d}: \tau=\left\{\begin{array}{l}7.301 s(0<s<0.75) \\ 7.301 s[1-\ln (0.575+0.345 s)](0.75<s<4.5) \\ 7.301 s[1-\ln (1.513+0.129 s)](4.5<s<8)\end{array}\right.$

$60 \mathrm{~d}: \tau=\left\{\begin{array}{l}11.562 s(0<s<0.85) \\ 11.562 s[1-\ln (0.884+0.460 s)](0.85<s<4.25) \\ 11.562 s[1-\ln (2.37+0.051 s)](4.25<s<6)\end{array}\right.$

$90 \mathrm{~d}: \tau=\left\{\begin{array}{l}4.14 s(0<s<1.6) \\ 4.14 s[1-\ln (0.433+0.362 s)](1.6<s<5.75) \\ 4.14 s[1-\ln (1.935+0.088 s)](5.75<s<8)\end{array}\right.$

\section{CONCLUSIONS}

- The bond force between CFRP bars and coral concrete is mainly composed of chemical adhesive forces, friction forces and mechanical occlusal forces. The bond slip curve can be divided into four stages: the slight-slip stage, slip stage, descending stage and residual stage.

- With the increase in the dry-wet cycle time, the ultimate bond strength of CFRP-reinforced coral concrete shows a trend of increasing first and then decreasing.

- Through fitting analysis, the bond-slip equation of CFRP-reinforced coral concrete is obtained. By defining damage variable $\mathrm{D}$, damage variable evolution models are obtained at different corrosion ages, and the constitutive model considering interface damage is established. 
Acknowledgments

The authors wish to acknowledge the financial support of "National Natural Science Foundation of China (Grant No. 51778577)", "Ningbo public welfare science and technology project (Grant No. 202002N3121)", "Ningbo traffic science and technology project (Grant No. 202007)" and Zhejiang Construction Research Project (Grant No. 2019K060).

\section{REFERENCES}

1. Qiao H., Tao Y., Zhuangzhi W., Xiaobing C., Yi D. (2016): Analysis of Life Cycle Cost of FRP Marine Coral Concrete Structure and Common Reinforced Concrete Structure. Construction Economy, 37(01), 61-66. doi: 10.14181/j.cnki. 1002-851x.201601061

2. Li X., Ma Y., Shen X., Zhong Y., Li Y. (2020): Study of Hydration and Microstructure of Mortar Containing Coral Sand Powder Blended with SCMs. Materials, 13(19), 4248. doi: 10.3390/ma13194248

3. Shen, J., Xu, D., Liu, Z., Wei, H. (2020): Effect of particle characteristics stress on the mechanical properties of cement mortar with coral sand. Construction and Building Materials, 260, 119836. doi: 10.1016/j.conbuildmat.2020.119836

4. Zhou, W., Feng, P., Lin, H. W. (2020): Constitutive relations of coral aggregate concrete under uniaxial and triaxial compression. Construction and Building Materials, 251, 118957. doi:10.1016/j.conbuildmat.2020.118957

5. Chen M., Geng J., Xiong H., Shang T., Xue C., Abbas M. (2020): Effect of Curing on Mechanical Properties of Cement-Stabilized Coral Sand in Marine Environment. Advances in Materials Science and Engineering, 2020, 4678376. doi: 10.1155/2020/4678376

6. Liu B., Guo J., Wen X., Zhou J., Deng Z. (2020): Study on flexural behavior of carbon fibers reinforced coral concrete using digital image correlation. Construction and Building Materials, 242, 117968. doi: 10.1016/j.conbuildmat.2019. 117968

7. Huang D., Niu D., Zheng H., Su L., Luo D., Fu Q. (2020): Study on chloride transport performance of ecofriendly coral aggregate concrete in marine environment. Construction and Building Materials, 258, 120272. doi: 10.1016/j.conbuildmat.2020.120272

8. Zhang L., Niu D., Wen B., Peng G., Sun Z. (2020): Corrosion behavior of low alloy steel bars containing $\mathrm{Cr}$ and $\mathrm{Al}$ in coral concrete for ocean construction. Construction and Building Materials, 258, 119564. doi: 10.1016/j. conbuildmat.2020.119564

9. Liu B., Guo J. H., Zhou J. K., Wen X. Y., Deng Z. H., Wang H. L., Zhang X. Y. (2020): The mechanical properties and microstructure of carbon fibers reinforced coral concrete. Construction and Building Materials, 249, 118771. doi: 10.1016/j.conbuildmat.2020.118771

10. de Sa F. R. G., Silva F. d. A., Cardoso D. C. T. (2020): Tensile and flexural performance of concrete members reinforced with polypropylene fibers and GFRP bars. Composite Structures, 253. doi: 10.1016/j.compstruct.2020.112784
11. Bazli M., Zhao X.-L., Jafari A., Ashrafi H., Bai Y., Raman R. K. S., Khezrzadeh H. (2020): Mechanical properties of pultruded GFRP profiles under seawater sea sand concrete environment coupled with UV radiation and moisture. Construction and Building Materials, 258, 120369. doi: 10.1016/j.conbuildmat.2020.120369

12. Bilotta A., Compagnone A., Esposito L., Nigro E. (2020): Structural behaviour of FRP reinforced concrete slabs in fire. Engineering Structures, 221111058. doi: 10.1016/j. engstruct.2020.111058

13. Li Y., Yin S., Lu Y., Hu C. (2020): Experimental investigation of the mechanical properties of BFRP bars in coral concrete under high temperature and humidity. Construction and Building Materials, 259, 120591. doi: 10.1016/j.conbuildmat.2020.120591

14. Tang Z., Li W., Tam V. W. Y., Yan L. (2020): Mechanical behaviors of CFRP-confined sustainable geopolymeric recycled aggregate concrete under both static and cyclic compressions. Composite Structures, 252, 112750. doi: 10.1016/ j.compstruct.2020.112750

15. Wang L., Zhang J. W., Huang C. S., Fu F. (2020): Comparative Study of Steel-FRP, FRP and Steel-Reinforced Coral Concrete Beams in Their Flexural Performance. Materials, 13(9), 2097. doi:10.3390/ma13092097

16. Wang L., Shen N., Zhang M. M., Fu F., Qian K. (2020): Bond performance of Steel-CFRP bar reinforced coral concrete beams. Construction and Building Materials, 245, 118456. doi: 10.1016/j.conbuildmat.2020.118456

17. Wang L., Zhang J. W., Chen W., Fu F., Qian K. (2020): Short term crack width prediction of CFRP bars reinforced coral concrete. Engineering Structures, 218, 110829. doi: 10.1016/j.engstruct.2020.110829

18. Wang L., Mao Y. D., Lv H. B., Chen S., L, W. (2018): Bond properties between FRP bars and coral concrete under seawater conditions at 30,60, and 80 degrees C. Construction and Building Materials, 162, 442-449. doi: 10.1016/j.conbuildmat.2017.12.058

19. Jun Y., Kim T., Kim J. H. (2020): Chloride-bearing characteristics of alkali-activated slag mixed with seawater: Effect of different salinity levels. Cement and Concrete Composites, 112, 103680. doi:10.1016/j.cemconcomp.2020.103680

20. Chao Y., Shutong Y., Dehai Q. (2018): Experimental study on the bond performance between BFRP bars and coral concrete. Engineering Mechanics, 35, (S1), 172-180.

21. Wang J., Yang J., Cui W. (2018): Effect of wet and dry cycles in salt solution on the interfacial bonding property of CFRP-concrete. Acta Materiae Compositae Sinica, 35, (8), 2055-2064.

22. Krajcinovic D. (2000): Damage mechanics: accomplishments, trends and needs. International Journal of Solids and Structures, 37(1-2), 267-277. doi:10.1016/s0020-7683 (99)00081-5

23. Xu Y., Qian C., Pan L., Wang B., Lou C. (2012): Comparing Monofractal and Multifractal Analysis of Corrosion Damage Evolution in Reinforcing Bars. Plos One, 7(1), e29956. doi:10.1371/journal.pone.0029956

24. Cauvin A., Testa R. B. (1999): Damage mechanics: basic variables in continuum theories. International Journal of Solids and Structures, 36, (5), 747-761. doi:10.1016/s00207683(98)00044-4 